\title{
Being Useful: How Information Systems Professionals Influence the Use of Information Systems in Enterprises
}

\author{
Hadi Karimikia \\ Auckland University of \\ Technology \\ hkarimik@aut.ac.nz
}

\author{
Dr Harminder Singh \\ Auckland University of \\ Technology \\ hsingh@aut.ac.nz
}

\author{
Dr Karin Olesen \\ Auckland University of \\ Technology \\ kolesen@aut.ac.nz
}

\begin{abstract}
Information systems (IS) researchers have developed various frameworks to understand the reactions of individuals to new information systems and their decisions to continue or discontinue their use. While routine use is usually enough to obtain the firstorder benefits of information systems once they have been deployed in an enterprise, more extensive and deeper use of these systems is needed to unlock their full potential. Encouraging individual employees to use information systems in this way often requires their IS colleagues to engage more fully with them to overcome uncertainties or a lack of training. This could take the form of IS professionals interacting with their non-IS colleagues formally or informally to provide relevant knowledge and guidance, and by taking the initiative to, for example, pre-empt challenges or develop useful tools. We draw on the concept of organizational citizenship behavior (OCB) to examine how the actions of IS employees can make it more likely for non-IS employees to engage in the deeper use of information systems. This study contributes to extending our understanding of the roles that IS employees play in improving the value that enterprises obtain from their IS investments, especially through their extra-role behaviors.
\end{abstract}

\section{Introduction}

Most organizations are under considerable pressure to make their operational and strategic processes more effective and efficient [10, 37, 67] and information systems (IS) are often used to achieve these goals. Once implemented, these systems need to be used appropriately by employees so as to obtain the outcomes their organization desires [23, 35]. However, such investments would have a more significant impact if users went beyond the routine use of these information systems to infuse them more deeply within their work practices [23, 69, 80]. An information system is infused in a work practice when it is used to its fullest potential $[23,79]$. While there has been extensive research on IS adoption and post-adoption issues [38, 47, 88, 89], less is known about the determinants of IS infusion [68, 80]. Research on these determinants has focused on the characteristics of information systems, such as the quality of the information and services they provide.

However, IS professionals, such as application developers, system administrators, and business analysts, also play a crucial role in encouraging employees to use information systems beyond what was prescribed or standardized, once they have gained experience in using the system [37]. IS staff in organizations facilitate IS implementation efforts with a blend of technical and non- technical skills, with the latter including formal communications and discretionary collaboration with their non-IS colleagues [7, 36, 63, 64, 67, 82]. IS staff members interact with their business peers to share their knowledge and skills, especially when the latter are using difficult-to-use technologies and face task-related conflicts from newlyadopted systems [42, 52]. The interaction between IS and non-IS staff often expands beyond formal communication into informal interaction, with IS professionals engaging in discretionary, prosocial behaviors toward business employees [21, 22, 66], influencing users' engagement with the new system [31].

This interaction between business and IS professionals is not clearly addressed in prior postadoption research [37]. Little attention has been paid to explain how the voluntary behaviors or informal activities that IS professionals carry out affect the perceptions of users and encourage them to use information systems as fully as possible and in novel, improvised ways. Thus, this paper's research question is: how does the informal interaction between IS and non-IS employees influence the inclination of non-IS employees to infuse information systems into their work practices?

Although individuals in organizations are social actors [45], post-adoption studies, such as Venkatesh et al. (2003), often limit their focus to their actions of managers and users without examining the 
role of IS professionals in supporting and motivating IS use. By not clarifying the role of IS professionals, current research has narrowed the social milieu that users exist in. This study has two contributions: i) explicating the impact of IS professionals on IS success beyond project implementation, and ii) defining additional mechanisms through which IS infusion takes place. The next section is an overview of the IS infusion literature. Next, we discuss the role of perceived usefulness and ease of use in influencing users to improvise with information systems, which leads to use beyond prescribed or mandated IS directions. Following that, we derive a set of discretionary behaviors that IS professionals have been known to engage in by reviewing the literature, and relate them to their impact on perceived usefulness, ease of use, and improvisation. We conclude with suggestions for testing the model.

\section{Conceptual Background}

\subsection{IS Infusion}

Cooper and Zmud (1990) categorize the deployment and use of information systems (IS) into six stages: initiation, adoption, adaptation, acceptance, routinization, and infusion. The first stage, initiation, refers to the search for a match between information technologies and organizational requirements. The steps include managerial decisions on which IT changes are needed, and the selection and planning of new information systems projects, in the form of innovations applied to organizational activities. This stage is followed by adoption, when these decisions lead to resources being invested to accommodate the implementation efforts. The third stage, adaptation, occurs when new IS systems are installed, developed, and maintained, while the acceptance stage refers to the direction of organizational effort toward the use of the new systems in organizational work processes and using them in a standardized way. The fifth stage, routinization, occurs when the new IS systems are used routinely and regularly, and are not perceived to be out of the ordinary.

Infusion, the last stage of IS implementation, refers to the achievement of a higher level of IS use that allows employees to exploit the full potential of the new systems. Terms similar to IS infusion include extended IS use, integrative IS use, and emergent IS use [69]. At this stage, employees leverage and use the new systems beyond their standardized usage, normal activities, or mandated IS use [69, 80]. The post-adoption literature argues that users use new information systems more extensively or infuse them into their work if they perceive the new systems to have a high degree of usefulness and are easy to use [16, 35, 68].

\subsection{Perceived Usefulness and Ease of Use}

Various models and frameworks have been used to study the perceptions of, intentions towards and behaviors around the adoption, continued use, and extended use of new information systems, such as the IS continuance model [38, 89], the post-adoptive behavior model [37], the technology acceptance model (TAM) and the theory of reasoned action [86, 88], the postacceptance IS usage behavior model [46], and the extended use behavior model $[35,68]$. Some of these models share the view that perceived usefulness and perceived ease of use are the strongest determinants of IS extended use. These two factors are in turn influenced by various antecedents, such as organizational conditions (e.g., the availability of required IT infrastructure and IS skills), individual beliefs regarding computer use, system characteristics, and social influence or norms (e.g., relationships between IS professionals in IS teams and business employees) [37, 86, 88].

These factors affect the intentions of users to continue using information systems, and continued use is an indicator of the success of an IS implementation. IS implementations are known to fail if users are not fully engaged in using new systems to their full potential $[1,74]$. Increasing the level of engagement so that a new system is infused into work practices may require the promotion of behavioral changes to replace a stable working-level set of routines with a dynamic workinglevel set of innovations [76]. These behavioral changes include voluntarily leading and scheduling IS project meetings [24, 90], spontaneous handholding, and knowledge-sharing [37].

These behavioral changes are voluntary, and are sustained by the interaction between IS professionals and their non-IS colleagues [37]. Through these interactions, end-users receive informal training or knowledge that makes the systems they sue less intimidating and easier to use. At the same time, endusers use this interaction to better understand how these new systems can help them with their specific work processes, thereby making the systems more useful. A key issue with the implementation of new systems is their fit with the way in which existing work processes were carried out, and how current work roles match the requirements of the new system [23]. New systems usually lead to changes in work processes, which are sometimes resisted by users even after the systems have been fully deployed [86] and can lead to systems being abandoned or worked around [1]. The probability of this occurring is higher if the systems have unfamiliar or unintuitive interfaces, making them difficult to use [68]. Thus, new systems are less likely to be resisted and conversely used more intensively and extensively if their ease of use is improved, through the provision of 
continuous, ad hoc and convenient training [47]. New systems are also more likely to be embedded into an organization's work processes if users are made aware of the systems' usefulness for their current and future needs [68]. This could happen through, for example, informing them about the capabilities of the system beyond the specific module used for their tasks, and of how other organizations used similar systems in novel ways. Such knowledge would stimulate a desire for improvisation and even encourage a band-wagon effect, as novel uses of the technology in one sub-unit are shared with others, leading to broader gains at the organizational level $[11,38]$.

\subsection{Improvisation}

Improvisation is defined as a set of unplanned actions in dealing with technology, which lead to unplanned changes in the processes of adoption or adaptation of new technologies $[18,55]$ or the implementation of new IT systems [26, 49]. Orlikowski's (2000) study of improvisation in technology adaptation examined how users facilitate adaptation processes, generating situated innovations in response to unexpected opportunities or unanticipated problems. Users with such improvisational behaviors go beyond the formal processes of IT use, typically generate new processes to experiment with technology, and implement new ways of working to use the technology. Ciborra (1999) asserted that improvisation takes place when existing and formal plans do not apply to novel situations at the appropriate time, and where key components, such as existing tacit and explicit knowledge, access to resources and the ability to deploy them, and environmental surprises, exist. Besides these, Orlikowski (2000) describes two additional components for success: support from managers and peers in encouraging improvisational behaviors, so that users are more likely to use technologies and involve outside-thebox thinking in their creation (e.g., workarounds). In order to understand how technologies are best used, Mendonca et al. (2006) suggested that both formal and informal training can support the occurrence of such improvisational behaviors.

Based on the preceding paragraphs, we propose that the informal positive behaviors displayed by IS professionals when they assist or support their non-IS peers (users) influence the latter's perceptions of the IS systems' ease of use and usefulness. This change in perceptions encourages users to improvise effectively, leading to the infusion of the information systems in their work practices.

\subsection{Social Cognitive Theory}

Theoretically, the improvisation process described above is supported by social cognitive theory
(SCT). SCT emphasizes that learning occurs in a social context through observation, and behaviors, cognition, and environmental events influence each other reciprocally [2, 4]. A key mechanism in SCT is behavior modelling, in which individuals' perceptions of their ability to perform expected behaviors is influenced by their expectations of valued outcomes [3, 33]. Observers who model their behavior vicariously will adopt and sustain such behavior if it meets their expectations regarding the likely outcomes. For example, computer training that improves users' selfefficacy leads to increased computer use, making users even more skillful and confident about IT [20].

Building on Bandura (2001), users who pick up IS adoptive behaviors easily through their interactions with other social actors are more likely to improvise with new systems. Informal interactions between IS professionals and users provide opportunities to model behaviors to users and affect their perceptions [45], so that they understand that using their new systems is easy and that these systems are more useful than the earlier ones. These interactions also enable users to evaluate potential consequences of their behaviors; for instance, gaining expertise on using a particular systems motivates users, because they can now become improvisers, rather than routine users.

\section{Support Provided by IS Professionals to Users}

The previous sections mentioned that actions to improve the perceived usefulness and ease of use of new information systems, and unplanned actions to come up with improvised solutions using the new information systems would make it more likely that they would be infused within organizations. Users who received additional, relevant and wide-ranging knowledge and support would be more likely to view new systems as being helpful and easy to use. Such knowledge is often available among the IS professionals in organizations. The more frequently IS professionals communicate and collaborate with their non-IS colleagues to share IS solutions or IT-related knowledge, the more likely it would be that their non-IS colleagues invest additional time and effort in improvising with their information systems, leading to a fuller extent of deployment in their organizations. Positive, discretionary interaction between IS and nonIS professionals, in which experienced IS professionals share prior useful experiences with IS users to avoid ITrelated failures, enhances the effectiveness of IS project implementation [93] by helping business employees have better experiences with newly-adopted technologies. 
Organizations are increasingly looking for “jack-of-all trades” or hybrid IS professionals to support their computing needs and to help them handle demanding IT situations [32, 72]. This refers to the growing need for IS professionals with technical IS skills and "soft skills" [40, 72, 83]. Soft skills include knowledge, skills, attitudes, and personal characteristics that can be improved with experience and/or training, and influence the task-related performance of non-IS users or IS project success [76]. Soft skills deal with the human aspects (e.g., communication and interpersonal issues) of the job of IS professionals, and are used when technical information is shared with their non-IS colleagues or when communicating with them socially [7, 41, 67, 82]. Enns et al. (2003) consider soft skills to include behaviors such as consultation, personal appeals, ingratiation, and interpersonal skills. They point out that chief information officers (CIOs) who only have technical skills are unable to influence other top executives or their peers, while CIOs with interpersonal skills are able to advance their relationships with others across the organization.

Heckman (1998) raised the question of the skills that IS professionals require, and demonstrated the essential skills in a pyramid model. He classified the skills into: technology, conceptual (e.g., system analysis), social (e.g., teamwork), and marketplace (e.g., business intelligence) skills. He also argued that these skills are used collectively and are manifested as positive, discretionary behaviors while collaborating with non-IS staff. For these behaviors to occur, strong social ties are needed, as networks of strong, personal relationships that have developed over time provide the basis for trust, cooperation and collective action [12, 24, 57, 73].

Tarafdar and Gordon (2007) studied the relationship between IS professionals and other units in the implementation of a health IS, and found IS professionals providing non-IS employees with troubleshooting, training, and voluntary handholding. While the technical expertise of IS professionals was expected by business employees, positive prosocial behaviors, such as voluntarily leading and scheduling IS project meetings [24, 90], spontaneous handholding, and information-sharing [37], were also carried out, even though they fall outside their formal job descriptions.

In the management literature, positive discretionary behaviors carried out by employees, as described above, are generally referred to as organizational citizenship behaviors (OCBs). This study draws on the concept of OCB to develop its arguments, and a short overview is presented here. OCBs are individual behaviors that are discretionary, not directly or explicitly recognized by the formal reward systems, and not prescribed in one's role requirements, such as assisting or supporting employees, or avoiding unethical behaviors in organizations [14, 54, 84]. These individual behaviors are also termed prosocial organizational behaviors [14], extra-role behaviors [85], and organizational spontaneity [29].

Podsakoff and his colleagues (2000) categorized OCB as: OCB toward individuals (OCB-I) or toward the organization (OCB-O). OCB-I behaviors, such as helping, cooperating behaviors (altruism and courtesy) and interpersonal facilitation, directly benefit individuals and indirectly benefit the organization. OCB-O behaviors benefit the organization directly, such as organizational loyalty, civic virtue, organizational compliance and conscientiousness [36, 59]. Recently, researchers have extended their understanding of OCB, so that it encompasses grouplevel behavior. Chen et al. (2005) term this group citizenship behavior (GCB) and conceptualize it as group-level behaviors that work groups engage in to support their group's performance and their organization's effectiveness. Group-level OCB has a positive impact on group performance, as well as group effectiveness [53, 58, 60]. Group-level OCBs, such as helping behaviors, are known to positively affect group performance beyond the impact of other group process variables, such as group cohesion, conflict, and leader effectiveness [27].

In the aggregate, such prosocial and extra-role behaviors improve organizational functioning [58, 59, 60] by improving employee performance, freeing up organizational resources, improving coordination, and enhancing the work climate [59]. In an information systems context, OCBs refer to the discretionary, positive behaviors IS professionals display when they assist non-IS colleagues informally and beyond explicit requests for assistance [71], which promotes IS infusion [43]. These behaviors can be categorized into: helping, knowledge-sharing, and initiative-taking.

\subsection{Helping}

Less expert IS users rely on more expert IS professionals to help them with a wide variety of IT knowledge or to update their IT expertise [66]. Since "give-help" and "get-help" behaviors are exchanged across an organization, IS helping behaviors have a positive impact on job performance and effective IS project implementation through interpersonal relationships [30, 66, 81, 93]. Helping is not only limited to face-to-face encounters, but also includes online helping behaviors or a remote IT help desk [91]. 
3.2.1.Online Helping Behaviors. Information systems enable employees to use web-based technologies, which provide IS professionals with new avenues to help their peers in the business units. Examples of web-based technologies are bulletin boards, web communities, and knowledge management systems. Constant et al. (1996) found out that IS professionals spent an average of nine minutes of their working time per day helping their peers or unknown employees by, for example, posting ideas or their prior experiences relevant to IT settings and IT configurations on bulletin boards.

3.2.2. IT Help Desk. IT helpdesk professionals display prosocial behaviors when they assist their peers who call in beyond what is expected from them. For example, they answer the same questions asked by the same person several times a day or search for answers about ambiguities related to the adoption of a new information system. Then, employees become more creative in their use of information systems after calling their IT help desk several times, and IT help desks played an important role in helping new employees adapt to the systems in use [9].

\subsection{Knowledge-sharing}

Knowledge becomes valuable when it is shared between an IS function and its business peers to improve job performance [42]. The extent of shared knowledge between IS and business units positively affects the performance of the IS unit [52], customer service [62], and project success [82]. For example, the extent of knowledge sharing is an important determinant of an effective ERP implementation through successful interactions between IS and business units [44]. IS professionals share their knowledge partly because less expert IS users often search for informal sources when they are dissatisfied with formal sources [66], and there is a good fit between business and IS professionals in terms of attitudes, language, personality, or perceptions [21, 22, 46]. Informal training between unit members from the same or different work units facilitates the sharing of knowledge in the use of IT-enabled work systems [37, 70].

3.3.1 Informal Training. The quality of knowledge of IS professionals is a key determinant of IS project success $[8,41]$. One way to improve IS professionals' knowledge is to train existing IS employees instead of recruiting new ones [32, 83]. Besides technical skills, IS professionals also need to be familiar with the work of the various business departments in the organization they work in [7]. Training is a method of sharing knowledge and expertise between organizational members and helps members achieve their goals and enhance their performance $[6,13]$. As formal training is costly, informal training, such as informal mentoring, can be used as an equivalent alternative $[65,66]$. In the IS context, peer mentoring refers to the matching of more experienced IS team members with less experienced non-IS team mates in a one-to-one relationship, so that the former can transfer their IT expertise to their junior colleagues $[15,51,66]$.

\subsection{Initiative-taking}

Initiative-taking has been found in IS contexts too. For example, Walz et al. (1993) observed 19 meetings of a software design team over four months. At the meetings, only a few participants demonstrated certain prosocial behaviors, such as punctual attendance, taking initiative, paying attention to the broader scope of the project, and performing additional tasks outside their job scope, such as communicating with external experts. Had such behaviors been exhibited by everyone else, the software that was designed would have been more effective and might have met the customer's satisfaction. Knowledge workers can be proactive and take steps to continually identify new work practices that may benefit their organization. For example, they can search for information that could help them create new ideas and knowledge [25]. As organizations adopt more and more IT systems increasingly frequently, IS professionals need to be creative to help their users carry out the work they used to do in the old IT systems with the new systems. Ghosh (2011) relates the experience of an IT service manager whose customers called his IT technicians to ask about information that was not stored in a new system. These requests led to the technicians learning the process for making new records, even though this task was not listed in their job description.

\section{Conceptual Framework}

This study focuses on the impact of positive, discretionary behaviors displayed by IS professionals and IS teams on users' perception of new information systems, which help users to carry out improvised actions to infuse IS systems into organizations. Social cognitive theory argues that social interaction supports the performance of behaviors, and that performance is motivated by the achievement of hoped-for outcomes. Thus, when IS professionals interact with their non-IS colleagues to assist them with IT needs and IS requirements, or when IS departments provide them with high-quality IS services, users are less likely to face any difficulties and barriers in utilizing the new information system. They perceive that the services they receive from the IS professionals and IS teams in 
their organization make it easier to accomplish their tasks and reduce their uncertainty around IT-related knowledge. Afterwards, the confidence that non-IS professionals gain through informal training and additional interactions with IS professionals enables them to spontaneously come up with IS solutions that are needed, and devise innovative ways of using their IS systems. This made it highly likely that they would use the newly-adopted technologies to a greater extent than they had expected to, leading to the infusion of the new systems into the organization. Even in the mandatory use context, users often limit their use of new systems until they are routinized into their work processes, where the new technology becomes part of the employees' workflow. However, obtaining the complete benefits of IS systems requires users to go beyond what is required of them to achieve the infusion of the new system in their workplace.

\subsection{Research Model}

Existing models on the extended use of systems or their infusion have been relatively silent on the role of IS professionals, and this study uses OCB to identify the behaviors of IS professionals that support a higher degree of IS use among users. The research model puts forward a new term of the role of IS professionals when additionally supporting non-IS colleagues in either their job-related performance or non-job-related responsibilities with different forms of IT and non-IT supports. Building on OCB and its dimensions, this research model proposes a corresponding IS-based construct based on the role of IS professionals (IS professionals' user support), which integrates all supportive activities they carry out to assist their non-IS colleagues, and conforms to the dimensions of OCB. Specifically, the different ways in which IS professionals support their users (e.g., IT helping, knowledge-sharing, informal training, and taking initiatives behaviors) aligns with the distinct aspects of OCB (e.g., altruism, courtesy, conscientiousness, civic virtue, and sportsmanship).

Figure 1 depicts the research framework that will be tested in this study. Positive, discretionary behaviors carried out by IS professionals are hypothesized to positively affect perceptions among users about the usefulness (H1) and ease of use (H2) of systems. Helping behaviors make systems easier to use as users receive support when faced with uncertainty. Knowledge-sharing improves the perceived usefulness of systems, because users gain a broader understanding of the features and potential of these systems. IS professionals who take initiative can be said to influence both attributes. Pre-empting a user's needs by providing a set of FAQs for a function he or she has not used yet but may do so in the future is an example of making a system easier to use. IS professionals who take an active interest in trends in the business processes of a unit they support so as to ensure that the systems can handle any changed requirements are making the system flexible and thus useful. These changes increase the self-efficacy of users, so that they are more likely to accomplish challenging goals [3].

Users are more likely to improvise with systems that are perceived to be more useful and easier to use, because these attributes affect the level of engagement users have with their systems. Systems that are easier to use encourage users to experiment with new ways of using them, i.e. improvise with them. So, the perceived level of usefulness and ease of use of a system influence the extent to which improvisation occurs (H3, H4). In turn, the level of improvisation influences the likelihood of the new system being infused into an organization (H5). The centrality of social interaction in the work of IS professionals means that engaging in such discretionary behavior is key for achieving outcomes that they value, such as the successful completion of software implementation projects and the assimilation of IT resources into organizational workflows.

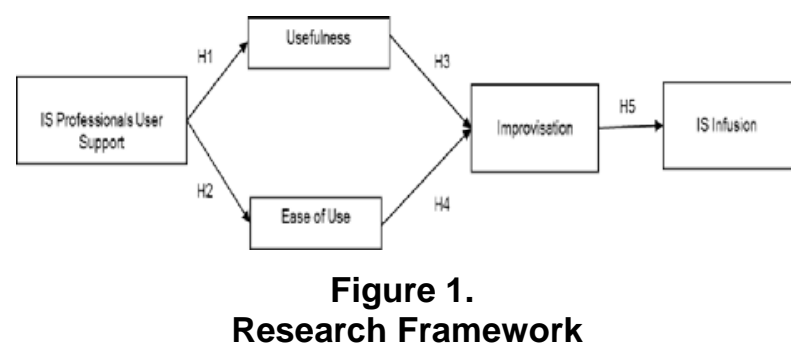

\section{Methodology}

A survey questionnaire will be used to gather data from business employees to answer questions about OCB behaviors exhibited by IS professionals and IS departments. Large organizations will be targeted as they have frequent and intensive interaction between their IS and non-IS staff, unlike small and medium firms. Also, participants should have at least two years of experience in using enterprise IT systems (e.g., ERP or CRM) in order to ensure sufficient time for IS infusion to occur $[35,43]$. The measures for the survey will be taken from existing studies (Table 1). Since the OCB constructs have been little used in the IS context, the instrument will be pre-tested by IS academics and professionals to establish content validity.

\section{Table 1.}




\section{Source of Constructs for Survey}

\begin{tabular}{|l|l|}
\hline Construct & Source \\
\hline $\begin{array}{l}\text { IS professionals' user } \\
\text { support }\end{array}$ & $\begin{array}{l}\text { Podsakoff et al. (1997) } \\
\text { (OCB-Group) }\end{array}$ \\
\hline Usefulness & $\begin{array}{l}\text { Venkatesh and Davis } \\
(2000)\end{array}$ \\
\hline Ease of Use & $\begin{array}{l}\text { Venkatesh and Davis } \\
(2000)\end{array}$ \\
\hline Improvisation & $\begin{array}{l}\text { Hmieleski and Corbett } \\
(2006)\end{array}$ \\
\hline IS Infusion & Jones et al. (2002) \\
\hline
\end{tabular}

Hypotheses 1 and 2 will be tested with multilevel analysis (the group-level independent variable IS professionals' user support will be regressed against the individual-level variables, usefulness and ease of use), while Hypotheses 3, 4, and 5 are individual-level analyses (individual-level usefulness and ease of use will be regressed against individual-level variable improvisation).

Multi-level structural equation modelling (MLSEM) will be used in this study to model the constructs, reduce the impacts of measurement error, and enable researchers to assess the fit of the model to data [61]. Various rules of thumb have been used to determine sample sizes. MacCallum, Brown, and Sugawara (1996) recommend that the sample size depends on the complexity of the model, such as having a few acceptable measures of a construct. Other researchers have mentioned a need of 10 respondents per indicator (or item) in determining a lower bound for the adequacy of sample sizes [75, 77, 92]. Therefore, based on the second group's definition, the rule of 10 is suggested to determine the total sample size for this research.

\section{Conclusion}

Theoretically, this study contributes by using social cognition theory to integrate the roles of IS professionals and users in enhancing IS infusion. To do so, the study identifies the positive and discretionary behaviors that IS professionals carry out informally to assist their non-IS peers, and the channels through which these behaviors affect IS infusion. By introducing the role of IS professionals in IS infusion, we are highlighting the need to consider the actions of the various actors in the social context surrounding information systems and their impact. As IS professionals analyze, plan, deploy, maintain or retire systems, their activities can influence the perceptions that users have of individual systems and the overall portfolio. Users make decisions to invest further time and effort in using new systems based on the availability of support in the organization, beyond the encouragement of their managers.

It is important to note that the paper focuses on only the positive aspects of IS professionals' postadoption activities. While it is well-known that IS professionals help users by offering technical support and facilitating knowledge sharing, it may be possible that IS professionals may also limit the post-adoption success of information systems. For example, if they are resistant to the new adopted system and provide only superficial support, it is unlikely that the system will be infused in an organization.

As IT becomes more pervasive and new systems are introduced more frequently, the informal relationships between users and their IS colleagues have a strong influence on their ability to use new systems. This study demonstrates the importance of discretionary collaboration in enhancing users' engagement with new systems and their ability to make full use of the opportunities inherent in them.

\section{References}

[1] F. Adam and P. O'Doherty, "ERP projects: Good or Bad for SMEs", Cambridge University Press, Cambridge, UK, 2003.

[2] A.Bandura, "Social Learning Theory", PrenticeHall, Englewood Cliffs, NJ, pp. 247, 1977.

[3] A.Bandura, "Social Foundation of Thought and Action", Prentice-Hall, Englewood Cliffs, NJ, 1986.

[4] A.Bandura, "Organizational Applications of Social Cognitive Theory", Australian Journal of Mnagement, Vol. 13, pp.275-302,1988.

[5] A. Bandura, "Social Cognitive Theory of Mass Communication," Media Psychology, vol. 3, pp. 265-299, 2001.

[6] R. Bapna, N. Langer, A. Mehra, R. Gopal, and A. Gupta, "Human Capital Investments and Employee Performance: An Analysis of IT Services Industry," Management Science, vol. 59, pp. 641-658, 2013.

[7] Bassellier and I. Benbasat, "Business Competence of Information Technology Professionals: Conceptual Development and Influence on ITBusiness Partnerships," MIS Quarterly, vol. 28, pp. 673-694, 2004.

[8] Bassellier, B. H. Reich, and I. Benbasat, "Information Technology Competence of Business Managers: A Definition and Research Model," MIS Quarterly, vol. 17, p. 159, 2001.

[9] A. Beaudry and A. Pinsonneault, "The Other Side of Acceptance: Studying The Direct and Indirect Effects of Emotions on Information Technology Use," MIS Quarterly, vol. 34, pp. 689-710, 2010.

[10] A. S. Bharadwaj, "A Resource-Based Perspective on Information Technology Capability and Firm Performance: An Empirical Investigation," MIS Quarterly, vol. 24, pp. 169-196, 2000.

[11] A. Bhattacherjee and G. Premkumar, "Understanding Changes in Belief and Attitude 
toward Information Technology Usage: A Theoretical Model and Longitudinal Test," MIS Quarterly, vol. 28, pp. 229-254, 2004.

[12] K. Blanchard, D. Carew, and E. Parisi-Carew, "How to Get Your Group to Perform Like A Team," American Society for Training and Development, vol.50, p. 34, 1996,

[13] G.-W. Bock, W. Zmud, Y.-G. Kim, and J.-N. Lee, "Behavioural Intention Formation in Knowledge Sharing: Examining the Roles of Extrinsic Motivators, Social-Psychological Forces, and Organizational Climate," MIS Quarterly, vol. 29, p. 87, 2005.

[14] A. P. Brief and S. J. Motowidlo, "Prosocial Organizational Behaviors," The Academy of Management Review, vol. 11, pp. 710-725, 1986.

[15] S. E. Bryant, M. Dan, and V. N. Thang, "A Field Study on Organizational Commitment, Professional Commitment and Peer Mentoring," Database for Advances in Information Systems, vol. 38, p. 61, 2007.

[16] J. C.-J. Chang and W. R. King, "Measuring the Performance of Information Systems: A Functional Scorecard," MIS Quarterly, vol. 22, pp. 85-115, 2003.

[17] X. P. Chen, S. S. K. Lam, S. E. Naumann, and J. Schaubroeck, "Group Citizenship Behaviour: Conceptualization and Preliminary Tests of its Antecedents and Consequences," Management and Organization Review, vol. 1, pp. 273-300, 2005.

[18] C. U. Ciborra, "The Platform Organization: Recombining Strategies, Structures, and Surprises," Organization Science, vol. 7, pp. 103-118, 1996.

[19] C. U. Ciborra, "Notes on improvisation and time in organizations," Accounting, Management and Information Technologies, vol. 9, pp. 77-94, 1999.

[20] D. R. Compeau and C. A. Higgins, "Application of Social Cognitive Theory to Training for Computer Skills," Information Systems Research, vol. 6, pp. 118-143, 1995.

[21] D. Constant, S. Kiesler, and L. Sproull, "What's Mine Is Ours, or Is It? A Study of Attitudes about Information Sharing," Information Systems Research, vol. 5, pp. 400-421, 1994.

[22] D. Constant, L. Sproull, and S. Kiesler, "The Kindness of Strangers: The Usefulness of Electronic Weak Ties for Technical Advice," Organization Science, vol. 7, pp. 119-135, 1996.

[23] R. B. Cooper and R. W. Zmud, "Information Technology Implementation Research: A Technological Diffusion Approach," Management Science, vol. 36, pp. 123-139, 1990.

[24] B. Curtis, H. Krasner, and N. Iscoe, "A Field Study of the Software Design Process for Large Systems," Communications of the ACM, vol. 31, pp. 12681287, 1988.

[25] K. H. Dekas, T. N. Bauer, B. Welle, J. Kurkoski, and S. Sullivan, "Organizational Citizenship Behavior: A Review and Qualitative Investigation of OCBs for Knowledge Workers at Google and beyond,"
Academy of Management Perspectives, vol. 27, pp. 219-237, 2013.

[26] A. R. Elbanna, "The Validity of the Improvisation Argument in the Implementation of Rigid Technology: the Case of ERP Systems," Journal of Information Technology, vol. 21, pp. 165-175, 2006.

[27] M. G. Ehrhart, P. D. Bliese, and J. L. Thomas, "UnitLevel OCB and Unit Effectiveness: Examining the Incremental Effect of Helping Behavior," Human Performance, vol. 19, pp. 159-173, 2006.

[28] H. G. Enns, S. L. Huff, and B. R. Golden, "CIO influence behaviors: the impact of technical background," Information \& Management, vol. 40, pp. 467-485, 2003.

[29] J. M. George and A. P. Brief, "Feeling good-doing good: a conceptual analysis of the mood at workorganizational spontaneity relationship," American Psychological Association, Inc,vol.112, 1992.

[30] S. Gosain, V. Venkatesh, and T. A. Sykes, "Coping with New Digital Networks: Understanding Employee Job Performance Using Social Network and Support Perpsectives."

[31] B. Ghosh, "GlobePort Faces Global Business Challenges--Assessing the Organizational Side of Information Systems Projects," Journal of Information Systems Education, vol. 22, p. 87, 2011.

[32] R. Heckman, "Planning to Solve the Skills Problem in the Virtual Information Management Organization, " International Journal of Information Management, vol. 18, pp.3-16, 1998.

[33] E. T. Higgins and J. A. Bargh, "Social Cognition and Social Perception," Annual Review of Psychology, vol. 38, pp. 369-425, 1987.

[34] K. M. Hmieleski and A. C. Corbett, "Proclivity for Improvisation as a Predictor of Entrepreneurial Intentions," Journal of Small Business Management, vol. 44, pp. 45-63, 2006.

[35] J. J. P.-A. Hsieh and W. Wei, "Explaining Employees' Extended Use of Complex Information Systems," European Journal of Information Systems, vol. 16, pp. 216-227, 2007.

[36] R. Ilies, J. D. Nahrgang, and F. P. Morgeson, "Leader-Member Exchange and Citizenship Behaviors: a meta-analysis," The Journal of Applied Psychology, vol. 92, pp. 269-277, 2007.

[37] J. Jasperson, P. E. Carter, and R. W. Zmud, "A Comprehensive Conceptualization of Post-Adoptive Behaviors Associated with Information Technology Enabled Work Systems," MIS Quarterly, vol. 29, pp. 525-557, 2005.

[38] X.-L. Jin, M. K. Lee, and C. M. Cheung, "Predicting continuance in online communities: model development and empirical test," Behaviour \& Information Technology, vol. 29, pp. 383-394, 2010.

[39] E. Jones, S. Sundaram, and W. Chin, "Factors Leading to Sales Force Automation Use: A Longitudinal Analysis," The Journal of Personal Selling and Sales Management, vol. 22, pp. 145156, 2002.

[40] D. Joseph, S. Ang, R. Chang, and S. Slaughter, "Practical intelligence in IT: Assessing Soft Skills of 
IT Professionals," Communication of the ACM, vol. 53, pp. 149-154, 2010.

[41] M. Keil, H. K. Lee, and T. Deng, "Understanding the most Critical Skills for Managing IT Projects: A Delphi Study of IT Project Managers," Information \& Management, vol. 50, pp. 398-414, 2013.

[42] W. J. Kettinger, C. Zhang, and K.-C. Chang, "Research Note-A View from the Top: Integrated Information Delivery and Effective Information Use from the Senior Executive's Perspective," Information Systems Research, vol. 24, pp. 842-860, 2013.

[43] H.-W. Kim, H. C. Chan, and S.-H. Lee, "A User Commitment Approach to Information Systems Infusion," Pacific Asia Conference on Information Systems, 2012.

[44] D.-G. Ko, L. J. Kirsch, and W. R. King, "Antecedents of Knowledge Transfer from Consultants to Clients in Enterprise System Implementations," MIS Quarterly, vol. 29, pp. 5985, 2005.

[45] R. Lamb and R. Kling, "Reconceptualizing Users as Social Actors in Information Systems Research," MIS Quarterly, vol. 27, pp. 197-236, 2003.

[46] G. Lee and W. J. Lee, "Altruistic Traits and Organizational Conditions in Helping Online," Computers in Human Behavior, vol. 26, pp. 15741580, 2010.

[47] X. Li, J. J. P.-a. Hsieh, and A. Rai, "Motivational Differences Across Post-Acceptance Information System Usage Behaviors: an Investigation in the Business Intelligence Systems Context," Information Systems Research, vol. 24, pp. 659-682, 2013.

[48] R. C. MacCallum, M. W. Browne, and H. M. Sugawara, "Power Analysis and Determination of Sample Size for Covariance Structure Modeling," Psychological Methods, vol. 1, pp. 130-149, 1996.

[49] S. Massa and S. Testa, "Data Warehouse-inPractice: Exploring the Function of Expectations in Organizational Outcomes," Information \& Management, vol. 42, pp. 709-718, 2005.

[50] D. Mendonca and F. Fiedrich, "Training for Improvisation in Emergency Management: Opportunities and Limits for Information Technology," International Journal of Emergency Management, vol. 3, pp. 348-363, 2006.

[51] J. Messersmith, "Managing Work-life Conflict among Information Technology Workers," Human Resource Management, vol. 46, pp. 429-451, 2007.

[52] K. M. Nelson and J. G. Cooprider, "The Contribution of Shared Knowledge to IS Group Performance," MIS Quarterly, vol. 20, pp. 409-432, 1996.

[53] T. M. Nielsen, G. A. Hrivnak, and M. Shaw, "Organizational Citizenship Behavior and Performance: A Meta-Analysis of Group-Level Research," Small Group Research, vol. 40, pp. 555577, 2009.
[54] D. W. Organ, "Organizational Citizenship Behavior," Academy of Management, vol. 3, pp. 7374, 1989.

[55] W. J. Orlikowski, "Improvising Organizational Transformation Over Time: A Situated Change Perspective," Information Systems Research, vol. 7, pp. 63-92, 1996.

[56] W. J. Orlikowski, "Using Technology and Constituting Structures: A Practice Lens for Studying Technology in Organizations," Organization Science, vol. 11, pp. 404-428, 2000.

[57] J. Peppard, "The Conundrum of IT Management," European Journal of Information Systems, vol. 16, pp. 336-345, 2007.

[58] Podsakoff, M. Ahearne, and S. B. MacKenzie, "Organizational Citizenship Behavior and the Quantity and Quality of Work Group Performance," The Journal of Applied Psychology, vol. 82, pp. 262270, 1997.

[59] Podsakoff, S. B. MacKenzie, J. B. Paine, and D. G. Bachrach, "Organizational Citizenship Behaviors: A Critical Review of the Theoretical and Empirical Literature and Suggestions for Future Research," Journal of Management, vol. 26, pp. 513-563, 2000.

[60] M. Podsakoff and B. MacKenzie, "Impact of Organizational Citizenship Behavior on Organizational Performance: A Review and Suggestion for Future Research," Human Performance, vol. 10, pp. 133-151, 1997.

[61] K. J. Preacher, "Multilevel SEM Strategies for Evaluating Mediation in Three-Level Data," Multivariate Behavioral Research, vol. 46, p. 691, 2011.

[62] G. Ray, W. A. Muhanna, and J. B. Barney, "Information Technology and the Performance of the Customer Service Process: A Resource-Based Analysis," MIS Quarterly, vol. 29, pp. 625-652, 2005.

[63] B. H. Reich and I. Benbasat, "Factors That Influence the Social Dimension of Alignment between Business and Information Technology Objectives," MIS Quarterly, vol. 24, pp. 81-113, 2000.

[64] B. H. Reich and I. Benbasat, "Measuring the Linkage between Business and Information Technology Objectives," MIS Quarterly, vol. 20, pp. 55-81, 1996.

[65] R. E. Rice, L. Collins-Jarvis, and S. ydney-Walker, "Individual and Structural Influences on Information Technology Helping Relationships," Journal of Applied Communication Research, vol. 27, pp. 285-309, 1999.

[66] J. W. Ross, C. M. Beath, and D. L. Goodhue, "Develop Long-Term Competitiveness Through IT Assets," Sloan Management Review, vol. 38, p. 31, 1996.

[67] K. A. Saeed and S. Abdinnour-Helm, "Examining the Effects of Information System Characteristics and Perceived Usefulness on Post Adoption Usage of Information Systems", Information \& Management, vol. 45, pp. 376-386, 2008. 
[68] V. L. Saga and R. W. Zmud, "The Nature and Determinants of IT Acceptance, Routinization, and Infusion," Proceedings of the IFIP TC8 Working Conference on Diffusion, Transfer and Implementation of Information Technology, pp. 6786, 1993.

[69] R. Santhanam, L. Seligman, and D. Kang, "Postimplementation Knowledge Transfers to Users and Information Technology Professionals," MIS Quarterly, vol. 24, pp. 171-199, 2007.

[70] S. Sawyer, K. Eschenfelder, A. Diekema, and C. McClure, "IT skills in the context of BigCo," Conference Proceedings ACM, pp. 9-18,1996.

[71] S. Sawyer, "Software Development Teams," Communications of the ACM, vol. 47, pp. 95-99, 2004.

[72] L. M. Rivers and J. Dart, "Sales Technology Applications: The Acquisition and Use of Sales Force Automation by Mid-Sized Manufacturers," Journal of Personal Selling \& Sales Management, vol. 19, pp. 59-73, 1999.

[73] J. B. Schreiber, A. Nora, F. K. Stage, E. A. Barlow, and J. King, "Reporting Structural Equation Modeling and Confirmatory Factor Analysis Results, A Review," Taylor \& Francis Ltd, vol. 99, pp.323, 2006.

[74] G. J. Skulmoski and F. T. Hartman, "Information Systems Project Manager Soft competencies: a Project-Phase Investigation," Project management Journal, vol. 41, pp. 61-80, 2010.

[75] D. S. Staples, I. Wong, and P. B. Seddon, "Having expectations of information systems benefits that match received benefits: does it really matter?," Elsevier B.V, vol. 40, 2002.

[76] B. M. Staw and R. D. Boettger, "Task Revision: A Neglected Form of Work Performance," The Academy of Management Journal, vol. 33, pp. 534559, 1990.

[77] S. Sundaram, A. Schwarz, E. Jones, and W. W. Chin, "Technology Use on the Front Line: How Information Technology Enhances Individual Performance," Journal of the Academy of Marketing Science, vol. 35, pp. 101-112, 2007.

[78] M. Tarafdar and S. R. Gordon, "Understanding the Influence of Information Systems Competencies on Process Innovation: A Resource-Based View," The Journal of Strategic Information Systems, vol. 16, pp. 353-392, 2007.

[79] L. Van Dyne and J. A. LePine, "Helping and Voice Extra-Role Behaviors: Evidence of Construct and Predictive Validity," The Academy of Management Journal, vol. 41, pp. 108-119, 1998.

[80] L. Van Dyne and L. Cummings, "Extra-role behaviors: The Need for Construct and Definitional Clarity," 50th Annual Meeting of the Academy of Management. San Francisco, CA, 1990.

[81] V. Venkatesh and H. Bala, "Technology Acceptance Model 3 and a Research Agenda on Interventions," Decision sciences, vol. 39, pp. 273-315, 2008.

[82] V. Venkatesh, M. G. Morris, F. D. Davis, and G. B. Davis, "User Acceptance of Information
Technology: Toward a Unified View," MIS Quarterly, vol. 27, pp. 425-478, 2003.

[83] V. Venkatesh, J. Y. L. Thong, F. K. Y. Chan, P. J. $\mathrm{H}$. Hu, and S. A. Brown, "Extending the Two-Stage Information Systems Continuance Model: Incorporating UTAUT Predictors and the Role of Context," Information Systems Journal, vol. 21, pp. 527-555, 2011.

[84] D. Walz, J. Elam, and B. Curtis, "Inside a Software Design Team: Knowledge Acquisition, Sharing, and Integration," Communication of the ACM, vol. 36, pp. 63-77, 1993.

[85] M. M. Wasko and S. Faraj, "Why Should I Share? Examining Social Capital and Knowledge Contribution in Electronic Networks of Practice," MIS Quarterly, vol. 29, pp. 35-57, 2005.

[86] H. R. Yen, E. Y. Li, and B. P. Niehoff, "Do Organizational Citizenship Behaviors Lead to Information System Success?," Information \& Management, vol. 45, pp. 394-402, 2008. 